\title{
Uses of the Present
}

\author{
STANLEY M. GARN \\ Center for Human Growth and Development, and The Nutrition Unit of \\ The School of Public Health and The Department of Anthropology, \\ University of Michigan, Ann Arbor, Michigan 48109-0406
}

\begin{abstract}
Working with the living, human biologists are in a fortunate position to put individuals and populations of the past in their appropriate quantitative places and to identify and comprehend environmental "stresses" of previous times. Although some writers have romanticized the human past as a diseasefree and natural existence, the evidence is strongly contradictory. Our ancestors and even our hominoid ancestors were much parasitized, with impairment of growth and function. Few had regular access to safe potable water. Their gritty diets were bacteria laden and often full of toxins, and the adequacy of diets was rarely predictable. High indoor occupancy rates facilitated the communication of respiratory diseases as well as mites, lice, fleas, and jiggers. Unventilated cooking and heating hearths made for elevated concentrations of carbon monoxide and particulate products of combustion. Living with animals, for warmth and protection, our Old World ancestors came to share their pathogenic fauna and so added tuberculosis, measles, influenza, smallpox, and numerous "plagues" to the list of human scourges. C) 1994 Wiley-Liss, Inc.
\end{abstract}

We human biologists work primarily with the living and that conveys numerous advantages. There is rarely any doubt about the sex of our subjects, their exact age, or their group affinities (unlike the situation with most archaeological material). As needed, we can assign socioeconomic status, which is a major determinant of body size, and can also assess degree of caloric adequacy and often nutrient levels. We can confirm paternity when we calculate sibling similarities and estimate heritability. Best of all we can accumulate samples of sufficient size for descriptive or comparative purposes, and thereby put fossil or subfossil individuals into their quantitative place.

Working with the living, we can show that many key fossils were not as thick skulled as they were supposed to be (our skulls get thicker as we grow older despite bone loss in the postcranial skeleton). With radiographic data on thousands of individuals, we can show that paleanthropic fossils and most hominoids did not fall outside of the "living" range with respect to metacarpophalangeal proportions. Measurements made on dental casts disclose the fact that some of us actually exceed type Neanderthals in crown-size dimensions and enjoy "fossil" molar size se- quences. From serial, longitudinal radiographs of growing children, we have shown that paleanthropic fossils were not unique in tooth formation sequences, quite paralleling information on emergence sequences ascertained from serial casts and large-scale population samples.

Detailed investigations on radiographs have provided much information on radiopaque "lines" and their meaning, starting with the fact that such lines and bands are actually spicules and bony networks within the marrow cavity. We know that many past populations seem to have higher line frequencies simply because the bony networks are far more visible on radiographs of dry bones than on in vivo radiographs of the living, still with their flesh. In each of these examples, and many others, the availability of living individuals provides a great advantage in the study of past populations and those fossils either ancestral to us or part of our phylogenetic tree. Knowing, as we do, how much human body size can be influenced by nutritional level, malabsorption syndromes, food intolerances, and parasites

Received December 21, 1992; accepted January 31, 1993.

Address reprint requests to the above. 
of all sorts, we are perhaps less prone now to see taxonomic meaning in simple size differences or even differences in "robusticity." This same knowledge, derived from studies of the living, makes us far more aware of the kinds of difficulties faced by past populations in acquiring safe food, finding potable water, and in responding to parasites of all sorts. There is good reason to believe that most of our ancestors had to breathe indoor air polluted by animal and human dander, insect and mice excreta, gases and particulate product of combustion to an uncomfortable and health-threatening degree. They also faced problems in the disposal of human and animal wastes, to the detriment of their health.

Contrary to romantic assumptions about "natural man," most of our ancestors probably did not enjoy pure foods, free of lifethreatening microrganisms or plant toxins, or hygienic living conditions, nor were they free from intestinal and other parasites. As we come to realize the health problems faced by hunters, grubbers, agriculturalists, animal-husbanders, and extending to neolithic communities and then city-states, we have new concerns about past populations and what can be seen in and inferred from their skeletal remains. The present, therefore, and knowledge of the present, has additional relevance to understanding of the past.

\section{IMPURE AND UNSAFE FOODS}

Those with a romantic turn of mind love to recall the foods of old, presumably "natural," uncontaminated by herbicides or pesticides, lacking additives and extenders, a treat both for the palate and the eye. Such selective recall selectively ignores the fact that foods were often unsafe to begin with, spoiled in shipping and storage, contaminated with insects and rodent excreta, sometimes naturally adulterated and even toxic.

Milk is a class example; before pasteurization and refrigeration, brucellosis, undulant fever, and bovine tuberculosis often came with the milk, a danger for children especially. Unrefrigerated from the dairy to the consumer, milk often arrived far less than fresh and in containers of questionable cleanliness. When milk production was down and the cows needed to be freshened, farmers often extended the volume with well water, untested as to bacterial content. Moreover, the milk frequently acquired "off" tastes, when the cows went to browse in mixed pastures, full of acrid herbaceous plants, or were fed spoiled silage.

Animal flesh presented numerous hazards, beginning with parasites that survived inadequate cooking, and a variety of bacteria (including Salmonella) that resulted from unsanitary butchering and handling. Without refrigeration, meat spoilage was frequent, especially in warm weather; this is one reason why spices and herb flavorings were long in demand. Hanging, drying, and smoking of meats and poultry added new possibilities for contamination. In the days before refrigeration, the extensive use of common salt and sodium nitrate for preservation had major effects on electrolyte levels when such preserved meats were much consumed.

Grains and grain products, however natural, were not necessarily safe or without undesirable additives. Wheat, rye, barley, and maize were subject to various fungal rusts, resulting in outbreaks of ergotism (a particular disadvantage to fetal development). Further, fungal growths also affected stored grains. In storage, insect and rodent contamination was inevitable (it is still true to some extent today), but storage pits and storage jars allowed a goodly portion of the stored harvest to be lost to insects and rodents.

Harvesting and milling techniques resulted in a considerable accretion of grit and little stones as we can see in the worn teeth of our Colonial ancestors, Bronze-age and Iron-age Europeans, and American Indians. (In many parts of the world today, bread is still quite gritty.) With storage, breadstuffs became subject to further insect infestation, as we learn from the reports of voyagers and sailors. Weevils were often a regular part of the daily bread.

Leafy vegetables were often fertilized with animal dung and human night-soil during the growing period, with direct enteric consequences. Moreover, weeds growing along with cultivars often included plants with interesting alkaloids, many of them in the tomato family that includes Datura, Belladona, and the like. Herbs or "yarbs," boiled and served, also afforded a variety of alkaloids, neurotoxins, and allergens.

Some cultivars are quite toxic, unless properly prepared, and these include cassava and sago. Indeed, the piths of some cas- 
sava cultivars are particulary difficult to prepare safely, and there are still many cases of cassava poisoning in Africa. The potato, in some of its cultivars, is also productive of toxins (although toxicity may be reduced by freeze-drying and further preparation.) Legumes can be a health problem, if improperly cooked, leading to lathyrism. And, of course, the disadvantages of the broad bean (the fava bean) and the winged bean to the genetically susceptible are well known.

\section{SLOW POISON}

Most food-borne infections due to unicellular organisms or viruses manifest themselves in a relatively short time and affect groups of individuals who have dined in common. Salmonella, the many enteric viruses, and staphylococcus species can bring an entire community into severe illness, often with a considerable loss of life. Some food toxins are equally speedy, whether, for example, from mushrooms, toxic fishes like the Fugu fish, or tainted shellfish following "red tides." Our ancestors must have experienced many such conditions (and food-borne epidemics are by no means uncommon today). Even sophisticated mycologists occasionally make mistakes in identification, and our ancestors were not as learned, silver spoons and "tasters" notwithstanding.

Multicellular organisms in the food chain may take longer to evidence their damages and trichinosis is one example. Groups of diners may come to share the muscle damage from this worm-like organism, with individual differences depending on the amount of infected flesh consumed, how well a particular portion had been cooked, and other individual factors. Effects of rustcontaminated grains can also be variable, and cumulative, increasing over a season and with particular impact on pregnant women and their fetuses, not evidenced until many months after ingestion. With such a time span between proximate cause and ultimate effect, witchcraft and divine punishment were favored explanations.

Some food toxins may take many years before their effects are demonstrable, and cycad toxicity is a prime example. The neurotoxin involved can manifest itself decades later by severe neuropathy (quite resembling some of the effects of a slow virus). Cycad meal, from some species that cover a wide range in the Pacific, has long been of concern to neurologists, and it is not easy to convince the cycad-meal eaters that the afflictions of their aged members are due to such a traditional food. A similar problem exists where fluoride levels are especially high (as around Lake Rudolph), resulting ultimately in narrowing of the channels in the vertebrae, and consequent late-adult neuropathy.

There is, moreover, reason to be concerned with heavy metals that enter the food supply from cooking utensils or storage vessels painted with colored earths or simply glazed with pigmented slips. Colored earths may also be used for food coloring, and (used as body paints) they may also enter into the food supply. We are now warned to avoid pitchers and vases purchased in native markets to store our orange juice and lemonade, but such health advisories are recent and still unknown in much of the world. Our last-century ancestors, of course, were much exposed to food-borne lead when they used pewter tankards, pitchers, and plates, when they stored their claret in lead-crystal decanters, when they used soldered tinware and solder-repaired ironware in their cooking, and when they consumed commercial foods sold in lead-soldered tins. In all probability, the entire Franklin expedition of 1845 succumbed to the lead from the soldered seams in the 'tin' cans that held their twoyear food supply.

\section{DON'T DRINK THE WATER}

Most of our municipal water supplies are now safe to drink, by most people, most of the time. With filtration, chlorination, and (sometimes) ozone treatment, levels of harmful micro-organisms are reduced to acceptable limits, at least at the water works. In many countries, however, safe water is not assured, even in the larger cities. Experienced travellers rely upon bottled mineral water $\sin$ gas, which may be unsafe water too.

Our immediate ancestors were not so fortunate; steams, lakes, and rivers were contaminated, especially in areas of higher population density. So they made extensive use of wine and beer as potable water. Even children were given beer to drink in Colonial times, and the ability to brew beer and ale for home consumption was an expected housewifely skill. In rural areas, well water was not necessarily safe, subject to runoff from manure piles and household privies, 
for the wells were located close to the house for convenience, and not too far from the barn.

As we know now, pristine lakes located amidst picturesque scenery are no guarantee of water safety, for animals use those lakes too. Many an outdoorsman has come down with "beaver belly" and there are microorganisms derived from moose, ducks, and geese as well. While swiftly running water coursing down gravelly stream beds does purify itself, in a way, quiet pools near the campsite must be viewed with particular suspicion.

For most communities in our historic and prehistoric past, a supply of pure water cannot be assumed. People washed their clothing and dumped their trash in the same water they used for drinking and cooking. They built their homes on higher ground adjacent to their water supply, and tilled their fields so as to assure drainage and runoff when it rained. They drove their domestic animals down to the river, lake or waterhole, assuring water contamination in the process. These various domestic activities could hardly be separated and there was no practicable way to keep the drinking water pure.

For still earlier hominids and hominoids, the question of water purity is of course conjectural, but animals were there, water holes served multiple purposes, and it was often necessary to drink brackish water or go without. We can only guess at how many episodes of dysentery and diarrhea that there were yearly or how many infants died because of bacterial and amoebic infections. For people at a low level of caloric adequacy, even a few diarrheal episodes per month can be fatal, and we know the toll from waterborne diseases in many parts of the world. Even in the last century in the United States summer diarrheas contributed to the high neonatal and infant mortality. Summerborn babies were at special risk, and there was (for years) a deficiency in the number of members of the American Association for the Advancement of Science born in June, July, and August!

Rather little attention has been given to water quality in ethnographic reports or in studies published by human biologists. Only recently has diarrhea been given serious attention as a limiting factor in child growth and development. Yet such water-borne diseases merit attention, especially where skeletal material allows the construction of life tables and in estimating rates of population growth. While some peoples did migrate in search of more adequate and nonseasonal water sources, they could not guarantee water purity. Besides, an adequate water supply encouraged a larger population density and more people to foul the water they drank.

\section{OUR LOAD OF FECES}

Each human adult excretes approximately $1 \mathrm{~kg}$ of fecal material per day. Much less may indicate a need for more fiber. Expressed on a yearly basis, the individual fecal contribution amounts to $365 \mathrm{~kg}$. For a population of just 100 , to keep calculations simple, the annual fecal load is just $38 \mathrm{En}$ glish tons (i.e., $36,500 \mathrm{~kg}$ ).

In our westernized cities, such waste tonnage is processed and dispersed through a complicated disposal system; then the effluvient is directed to a convenient river, lake, or into the sea. Large modern cities, numbering in the millions, could not exist without such provisions, originally developed by Roman sanitary engineers (the Cloaca Maxima being the type example).

Rural areas, of course, lack such disposal systems, and people depend on septic tanks, latrine pits, and dung pits, which may contaminate their wells when there is runoff or when the water table becomes high. Most of the world lacks even these niceties and most of our ancestors were not so provided. In medieval towns, human excreta were simply dumped next to the houses or outside the village walls. York, in England, was famous for the odor of decaying fecal material, and in Montreal, excreta and garbage collected along the back alleys little more than a century ago.

Many people still deposit their excreta in shallow pits near their habitations, or directly on the ground, both for convenience and after-dark safety. Despite the action of soil bacteria and dung-beetles, the decomposition products lend a characteristic odor, easily noticed down-wind. Following rain, these products of the human gastrointestinal system may contaminate water supplies whether they are simple dug wells or ponds or pools or streams. Lacking rain, such fecal deposits dry out and get distributed by the wind as in the unplumbed villages around Mexico City. Either way, bacteria and viruses and parasites become well distributed in a matter of time. For slash-and-burn agri- 
culturalists and peripatetic planters, one generation's defecations may contaminate the soil tilled by many later inhabitants. Public health specialists working in Central American villages have attempted to introduce latrines in the effort to minimize fecalborne diarrheas and parasitic episodes, but sitting on a wooden platform is often viewed as uncomfortable and conducive to constipation by the peoples so instructed.

With due admiration for the Roman engineers and for Thomas Crapper (who gave us the anti-syphon positive-flush toilet), we must give much attention to the problems of fecal disposal and cross-infections for most past populations, back to our hunting and gathering ancestors. Even when night-soil was not used as a no-cost fertilizer, agriculturalists defecated in their fields and contamined their leafy crops in the process. Though migrant peoples (like Australian aboriginals on walkabout) may have outwalked their fecal deposits some of the time, tribal congregations and sedentary periods could increase the risks from improperly disposed feces. Domestic animals (fowl, sheep, cattle, and dogs) added to the amount of dung deposited on the land surface, leached into water supplies after the rain, or dried and blown as fine dust in windy, arid highlands.

To return to the tonnage of human waste produced by a relatively small population in the course of a single year, and without estimating the potential accumulation over a decade or a century, there is good reason to give renewed attention to the waste problems and health in our ancestral pasts.

\section{THE PARASITES IN OUR PAST}

There are dozens of intestinal parasites popularly known by their shape: round worms, flatworms, hairworms, tapeworms, pinworms, hookworms, whipworms, etc. Some are passed from person to person and some are transferred from animals to people, and vice versa. Depending on the degree of parasitic infection, the type of parasite and individual differences, the symptoms may range from mild discomfort to acute distress. Children so affected may fail to grow; they are then far more likely to develop protein-calorie malnutrition and succumb.

Other parasites may establish themselves in the heart chambers (cf "heartworm in dogs"), in skeletal muscle, as in trichinosis, or in the lymphatic system, leading to ele- phantiasis, or in the prostate and vagina. Some parasites become established in the eye, resulting in blindness, or in the liver with consequent hepatic damage. Flies, snails, drinking water, bird droppings, and contaminated flesh are some of the sources of these parasites which are more common in the tropics but now increasingly found in more temperate places.

It was once thought that the common intestinal parasites were restricted to the Old World before Columbus, and that American Indians were free from their presence in preColonial times. More recently, studies of skeletal remains, latrine pits, defecation sites, etc., have shown that the Indians of North America were often parasitized well before 1492. Paleoparasitologists have demonstrated high levels of parasitism in American Indian coprolites from many parts of the United States, and they have shown that the Anasazi were especially prone to parasites (presumably because they practiced irrigated agriculture). So, we may conclude that no human group was without its load of parasites.

Chimpanzees in the wild are also subject to parasitic infections, with over one-half of some individuals afflicted at any given time. While there is much interest now in their use of bitter-tasting plants with antihelminthic properties (primate self-medication), the inescapable conclusion is that none of our ancestors was parasite free, over a period of millions of years.

The implications to growth, reproduction, and infant mortality are obvious, especially where skeletal remains indicate high infant mortality, and in Third World countries where one-half of neonates never live long enough to go to school. There is compelling need, therefore, to review our thinking about population dynamics, and in particular reference to places like the American Southwest, where many groups became extinct before the arrival of Spanish explorers. It is probably premature to attribute such depopulation to agricultural attainments that increased the risk of heavy parasitization, but parasite densities and not just single-cereal agriculture may be taken into account.

Conversely, population expansion and runaway population growth may also be seen as a result of safer water supplies (the "pipe" as they called it in highland Guatemala), more effective disposal of human and 
animal wastes, and such simple health precautions as hand-washing, flush toilets, meat inspection and refrigeration, and the lesser use of raw meat. Fish and shellfish are still a source of intestinal parasites that survive near-freezing temperatures and thrive in the icebox. In any event, paleoparasitologists have given us much to consider, including the need to test our Third-World subjects for parasites when we study their growth, or their fitness, or their cognitive development. It is only a few decades since hookworm was a pervasive public health problem in many parts of the United States, especially the Old Confederate South. Shoes, sanitation, and education all helped to diminish the hookworm scourge, but pediatricians still have to peruse the appropriate pages in the American Academy of Pediatrics' "Redbook" to keep abreast of parasites, their symptoms and their treatment.

\section{THE FOUL AIR WE BREATHED}

Most of us live and work in nice comfortable buildings, temperature-controlled against winter cold and summer heat. Municipal regulations now limit the number of people per room to assure hygienic living conditions, and (in the workplace) cigarette smoking no longer fouls the air. Nonetheless, the Environmental Protection Agency (EPA) is increasingly concerned about pollutants that we breathe indoors, gases derived from plastics and paints and formaldehyde from particle board and plywood used in modern construction. Tight windows and weatherstripping keep out drafts, but serve to minimize air changes as well.

Our ancestors had it much worse, though their homes, hovels, and huts were scarcely airtight. Occupation densities were far higher, for indoor space was expensive and people huddled together for warmth and companionship. Often there was only a few square feet per person in long-houses, crofters huts, tepees, hogans, adobe dwellings, or in the "Saxon houses" used in Norway. The occupants breathed and rebreathed each other's expired air, increasing the risk of respiratory disease. In most places and most eras bathing was uncommon, and clothing was rarely washed. Besides, straw bedding was standard, releasing clouds of dust and housing a considerable insect population which contributed their excreta to the atmosphere indoors. Dirt floors were the rule, even in late
Colonial times, and the dust mites thrived in the billions. In such atmospheres, the allergic among our ancestors must have experienced constant discomfort.

People often lived with their animals, also bedded in straw, for protection against loss and for shared warmth. Animal exhalations, animal dander, and dried animal excreta were, therefore, added to the indoor air, which could become heavy with methane and the decomposition products of urea. As chickens often shared the living-quarters, too, their contributions added to the foul air, until their excreta were finally swept up and deposited outside the door. Living in close proximity with animals gave our old World ancestors tuberculosis, influenza, measles, and smallpox among the other diseases that followed Columbus into the New World.

Heating was simple, using sticks or brush or dried dung burned in elementary hearths, with no more than a smoke-hole for venting and often not even that. (The brick fireplace and chimney is a recent invention, and most of the world's peoples still lack that nicety in their habitations.) Shutters, matting, and animal-skin hangings served to moderate drafts and to keep the warmth indoors. So people were much exposed to the various gases of combustion, and to the particulate material generated by smouldering fires. The cozy peat hearths of Ireland and Scotland left a constant haze indoors, which the Gaels inhaled at every breath.

In the tropics, air-tight habitations were rarely needed, but smoke served a useful purpose indoors at night, keeping insects at bay. So one still sees simple straw and palmetto huts, built on stilts to thwart rodents and snakes, but with adjustable hangings to keep the smoke in and the flying-insects out. Indoor smoke inhalation was, therefore, not limited to colder climates or wintertime in moderate climates, and must have contributed much respiratory distress in most places at most times in our prehistoric past.

House dust and mould spores are problems to the afflicted among us, necessitating electrostatic air cleaners and careful choice of furnishings. Even so, the dust mites that share our beds and carpetings, living off our exfoliated skin flakes, make life miserable for the susceptible. Consider, therefore, the indoor experiences of most of our ancestors, living in heavily tenanted habitations, several liters of water exhaled every day by each occupant, and with rugs, rags, animal 
skins, and unwashed beings serving to breed moulds and to sustain billions of mites and larger insects as well.

Of course, indoor air quality was not equally bad in yurts, crofts, hogans, igloos, cliff-dwellings, tepees, and rock shelters, in the crowded tenements of Hogarth's time or those of the Lower East Side of New York. But the indoor air our ancestors breathed and shared would not meet modern EPA standards. And they were at continual risk for respiratory diseases even when the outside air was clean and pure. (Actually the latter statement must be hedged somewhat, for in many parts of the world wind-blown dust and dirt is a recurrent phenomenon at several times in the year.) So people huddled indoors to escape the dust storms and sand storms, enduring indoor pollution as they sought refuge from the dust and sand billowing without.

\section{USING THE PRESENT TO COMPREHEND THE PAST}

As mentioned at the beginning, the human present allows us the ability to put hominoids and hominids of the past in perspective, both with respect to dimensions and proportions and with regard to developmental sequences, i.e., the order of developmental events. With metric and radiogrammetric data on thousands of living individuals now available, it is possible to ascertain the extent to which any fossil or subfossil individual falls within our centiles or whether is truly beyond the 95th or 99th centile range of today. Surprisingly often, even for Australopithecine teeth, such specimens prove less extraordinary than their original describers suggested, so that there may be more taxa in our textbooks than the metrics can truly support. Data on sequences or orders of epiphysical union or of tooth formation and emergence also suggest fewer "taxonomic chasms" than we were led to believe, though major differences in sequences (with little overlapping) may, by themselves, document quantum evolutionary steps.

Apart from the metrics, including bone mass/bone volume comparisons, we enjoy the great advantage of knowing about health conditions and risk factors that our ancestors may have experienced. We can now ask whether any of our ancestors and collaterals were "healthy," in the medical examination sense, whether they had enough to eat at the time of weaning, whether they had access to safe foods during the growing period, and whether they were parasitized during much of their life. Knowing, as we do, that inadequate caloric and nutrient intakes can subtract $10 \mathrm{~cm}$ or more from adult stature, we can review our comparisons of past populations and the generalizations we have made about the possible effects of latitude. What with caloric malnutrition and parasitization, we can rethink apparent temporal (or secular) changes, in both directions. Even our last century grandparents experienced cyclical changes in food availability, due to drought and crop failures and seasonal shortages, directly reflected in child growth rates. Droughts and famines in North Africa, India, and the Sudan document great fluctuations in food availability, and therefore, mortality, such as peoples have long experienced.

It is popular now to talk about environmental "stresses," with the term stress often imperfectly defined. With our knowledge of the present, however, we can be far more precise in regards to stresses, though they are often interrelated. Caloric inadequacy, chronic or acute, is one very real stress but it is often combined with low levels of quality protein. Parasite infection is another stress, but it is commonly associated with blood loss and iron deficiency anemia. Weaning stress is increasingly understood, since most weaning foods or "paps" are inferior to maternal milk. Pregnancy stress is the subject of much concern in the Third World, where low pregnancy weight gains reflect an actual loss of maternal tissues (and inadequate fat storage to sustain lactation). However, men on the hunt or warpath experience negative nitrogen balance as their energy expenditures exceed their energy intakes, and boys coming into adolescence may be much stressed by the treks, searches, and assigned missions that are common concomitants of coming-of-age puberty ceremonies. Fasting and food taboos in menstrual huts also produce nutritional stresses when menarche is so celebrated.

Fortunately for our attempts to understand the human bioenergetic past, though unfortunately for some of the individuals involved, we are still in a position to investigate many of these stressful conditions and their effects on growth, reproduction, morbidity, and mortality. We can still go into huts and hovels and measure air quality in - 
side. We can count and identify the patho- addition to our traditional metrics and analgens in prepared food and drinking water, yses of sequences of development, we are and we can measure the amount of grit, silt, increasingly able to use the human present and nonnutritive ash that people consume both to illuminate and to comprehend our with their daily breads. By so doing, and in evolutionary past. 